\title{
Clinical features and outcome of mixed connective tissue disease in developmental age - observational study from one center
}

\author{
Lidia Rutkowska-Sak, Piotr Gietka \\ Clinic of Developmental Age Rheumatology, National Institute of Geriatrics, Rheumatology and Rehabilitation, Warsaw, Poland
}

\begin{abstract}
Objectives: Mixed connective tissue disease is a rare systemic connective tissue disease of developmental age and it includes the features of arthritis, polymyositis/dermatomyositis, systemic lupus erythematosus and systemic sclerosis, with presence of anti-ribonucleoprotein antibodies (anti-RNP) in serum. Early diagnosis of the disease is difficult but essential in preventing development of systemic complications, which are often irreversible. International literature does not report many studies on large cohorts of children with this disease. The aim of this retrospective study was to define clinical characteristics and long-term results of treatment of the disease in 60 children with mixed connective tissue disease hospitalized in the period between 1978 and 2018. The diagnosis was established on the basis of Kasukawa's criteria.

Material and methods: It was a group of 60 children (46 girls and 16 boys) aged 10.5 on average (4-16.5). When assessing general symptoms at the onset of the disease according to Kasukawa's criteria, the highest number, over $80 \%$ of children, demonstrated symptoms suggesting SLE, about $40 \%$ suggesting DM and about $25 \%$ suggesting SSC. In the period of observation the number of children with clinical symptoms suggesting SSC increased. The most common clinical symptoms included Raynaud syndrome, arthritis and myositis and the most common irregularities in the test results included presence of anti-RNP antibodies and rheumatoid factor and hematological symptoms such as leukopenia/thrombocytopenia. Restrictive lung function impairment was demonstrated by $20 \%$ of children. Treatment most often included combined therapy (glucocorticosteroids + methotrexate/azathioprine).

Results: In $70 \%$ of the patients stable improvement was observed. Remission concerned $7 \%$ of the patients, frequent exacerbations were found in almost $20 \%$ of patients, and 2 children (3.5\%) died. Conclusions: The long term observations of patients in developementeal age with mixed connective tissue disease revealed that the majority of them had domination of SLE symptoms, only in 7\% achieved remission and $70 \%$ remained in stable improvement. Serious infections with septic state were the cause of death in two cases.
\end{abstract}

Key words: mixed connective tissue disease, clinical symptoms, prognosis.

\section{Introduction}

In 1971 Sharp et al. [1], from among inflammatory connective tissue diseases, distinguished a clinical entity which they named mixed connective tissue disease (MCTD). The disease was described for the first time in 1972. Soon, there were reports on the infantile form of MCTD [2, 3]. Mixed connective tissue disease is characterized by concomitant occurrence of clinical symptoms typical of systemic lupus erythematosus (SLE), systemic sclerosis (SSc), dermatomyositis (DM) and sometimes also juvenile idiopathic arthritis (JIA), without meeting clear diagnostic criteria for those diseases. This is what distinguished MCTD from overlap syndrome, and defining criteria for the disease exclude diagnosis of undifferentiated connective tissue disease (UCTD).

The presence of anti-ribonucleoprotein antibodies (RNP) in patients' sera is an immunological marker of

\footnotetext{
Address for correspondence:

Lidia Rutkowska-Sak, Clinic of Developmental Age Rheumatology, National Institute of Geriatrics, Rheumatology and Rehabilitation, 1 Spartańska St., 02-637 Warsaw, Poland, e-mail: lidia.rutkowska-sak@spartanska.pl 
MCTD. The antibodies are directed primarily against the protein bound with one of the small nuclear ribonucleases, U1snRNP, with molecular weight of $70 \mathrm{kDa}$, detected via immunoblotting [4].

Disease etiology includes: influence of genetic factors (such as presence of the HLA, DRB1, HLA-DR4 and HLA-B8 histocompatibility antigens), environmental factors (female sex hormones, Cytomegalovirus and Epstein-Barr virus, retroviruses, exposure to chemical factors such as vinyl chloride, silicon compounds, some drugs, e.g. procainamide) and congenital and inborn immune response disorders [5-7].

Histopathological changes are observed in many organs and joints and they consist in infiltrations com-

Table I. Diagnoses on admission to the clinic

\begin{tabular}{|lcc|}
\hline Diseases & $n$ & Percentage \\
\hline $\begin{array}{l}\text { Mixed connective tissue } \\
\text { disease }\end{array}$ & 30 & 50 \\
\hline Juvenile idiopathic arthritis & 18 & 30 \\
\hline Systemic lupus erythematosus & 6 & 10 \\
\hline Dermatomyositis & 3 & 5 \\
\hline Systemic sclerosis & 1 & 1.6 \\
\hline Rheumatic fever & 1 & 1.6 \\
\hline Inflammatory bowel disease & 1 & 1.6 \\
\hline
\end{tabular}

Table II. Children that meet Kasukawa's criteria

\begin{tabular}{|lcc|}
\hline Criteria & $n$ & Percentage \\
\hline I. Common symptoms & & \\
\hline Raynaud syndrome & 43 & 75 \\
\hline Swollen fingers & 21 & 35 \\
\hline II. Anti-RNP antibodies U1 & 60 & 100 \\
\hline III. Mixed symptoms & & \\
\hline A. That suggest SLE: & & \\
- polyarthritis & 43 & 75 \\
- $\uparrow$ lymph nodes & 3 & 5 \\
- facial erythema & 15 & 25 \\
- pericarditis/pleuritis & $6 / 5$ & $10 / 8.3$ \\
- leukopenia/ & $26 / 14$ & $43.3 / 23.3$ \\
$\quad$ thrombocytopenia & & \\
\hline B. That suggest SSC: & & \\
- sclerodactyly & 16 & 26.6 \\
- pulmonary fibrosis/lung & $0 / 12$ & $0 / 20$ \\
$\quad$ function impairment & & \\
- oesophageal & \\
$\quad$ dysmotility/dilation & 7 & 11.6 \\
\hline C. That suggest DM or PM: & & \\
- muscle weakness & & \\
- $\uparrow$ CPK in serum \\
- myogenic EMG result
\end{tabular}

posed of lymphocytes and plasma cells in the tunica intima and possibly in the tunica media of small and large blood vessels, with presence of $\operatorname{lgG}$ and $\lg M$ and complement [8].

Frequency of the disease is unknown. Scarce epidemiological studies in adults define the incidence as 2/100 000 per year, and prevalence as 3.8/100 000 . Most authors report significant predominance of females among patients. 7-23\% of cases are observed in developmental age [9]. It is debatable whether in developmental age the disease is milder or more acute $[9,10]$.

The commonly known classification and diagnostic criteria published so far have not been widely accepted. These include the so-called Sharp's criteria, Alarcón-Segovia criteria, Kasukawa's criteria, and Kahn and Appelboom's criteria [11-14]. Due to the lack of uniform, international consensus, various criteria are applied to scientific studies. In recent years Lage et al. [15] offered preliminary criteria for the disease activity. The criteria include major symptoms (cutaneous vasculopathy, impaired lung functions, symptoms from central nervous system and kidneys), minor symptoms (arthritis, rash, diarrhea, mild myositis, weight loss) and irregularities in laboratory test results (lymphopenia/thrombocytopenia, elevated ESR/C-reactive protein, elevated immunoglobulin $\mathrm{G}$ levels). An algorithm that allows the disease to be classified as active is as follows: presence of two major symptoms or of one major and two minor symptoms or of three minor symptoms with presence of irregularities in laboratory test results. There are no criteria for remission [15].

It should be mentioned that among known rheumatologists there are such doctors as Smolen and his colleagues who initially denied the existence of MCTD as a separate disease entity but later changed their mind $[16,17]$.

\section{Material and methods}

The retrospective study included a group of patients hospitalized in the period between 1978 and 2018, who were finally diagnosed with MCTD. The diagnosis was established on the basis of Kasukawa's criteria [13].

It was a group of 60 children (46 girls and 16 boys) aged 10.5 on average (4-16.5); 36 children were above 10 years of age. The time needed for diagnosing the disease was 1.8 years on average (2/12-10), and observation time was 6 years on average (2/12-14).

\section{Results}

There were various diagnoses which were the cause for referring the children to the clinic. They are presented in Table I. 
Numbers of children in whom symptoms and abnormalities in laboratory test results suggesting diagnosis of MCTD according to Kasukawa's criteria were observed are presented in Table II.

Clinical symptoms not included in Kasukawa's criteria, observed in examined patients are presented in Table III.

Improper results of laboratory tests not included in Kasukawa's criteria, observed in examined patients are presented in Table IV.

Table $V$ presents general assessment of 57 examined children after an average of 6.1 years of observation. There was no information on 3 patients.

Onset of the disease in the observed children was acute or sub-acute in character. In $50 \%$ of cases, the variability of symptoms was the cause of diagnoses other than MCTD listed on referral to the clinic. Fever, sometimes hectic and persistent in character, was found in almost half of the cases. In those children, elevated laboratory indicators of an acute inflammatory process were observed later on. Hypergammaglobulinemia was observed in all the patients. When using criteria of Lage et al. [15], all the children could have been diagnosed with high clinical and laboratory activity of the disease.

The picture of the disease was dominated by Raynaud syndrome. Pains or other signs of arthritis, found in $75 \%$ of children, mostly included many joints, mainly wrist, interphalangeal hand, elbow and ankle joints. In $15 \%$ of children morning stiffness was recorded, in $10 \%$ overgrowth of synovial membrane in ultrasound assessment, mostly in wrist joints, and in some children erosions on the surface of the joints could be seen in ultrasound examination. Restriction of mobility of joints usually was functional in character, as in Jaccoud's arthropathy. In 2 children we observed persistent, numerous nodules on the extension surface. Very diverse skin lesions, which are presented in the table, were typical for DM or SLE or SSC, and had a stable picture.

Table III. Other clinical symptoms in examined children

\begin{tabular}{|lcc|}
\hline Other clinical symptoms & $n$ & Percentage \\
\hline Fevers & 26 & 43.3 \\
\hline Heliotrope erythema around & $33 / 19.8$ & $55 / 33$ \\
\hline The eyelids/Gottron's sign & 9 & 15 \\
\hline Morning stiffness & 6 & 10 \\
\hline $\begin{array}{l}\text { Overgrowth of synovial } \\
\text { membrane in joints }\end{array}$ & 12 & 20 \\
\hline Symptoms of dryness & $3 / 3 / 3$ & $5 / 5 / 5$ \\
\hline $\begin{array}{l}\text { Muscle calcinosis/ } \\
\text { subcutaneous nodules }\end{array}$ & $2 / 2$ & $3.3 / 3.3$ \\
\hline
\end{tabular}

Table IV. Improper results of laboratory tests in examined children $(n=60)$

\begin{tabular}{|c|c|c|}
\hline Results of laboratory tests & $n$ & Percentage \\
\hline Anaemia & 27 & 45 \\
\hline$\uparrow \mathrm{ESR} / \uparrow \mathrm{CRP} / \uparrow$ fibrinogen & 30 & 50 \\
\hline$\uparrow \alpha 2-/ \uparrow$ gammaglobulins & 30 & 50 \\
\hline Rheumatoid factor & 47 & 78.3 \\
\hline Anti-SSA antibodies & 12 & 20 \\
\hline Anti-SSB antibodies & 4 & 6.6 \\
\hline LAC & 10 & 16.6 \\
\hline ACL antibodies (IgG, IgM) & $\begin{array}{l}\text { 3/27 examined } \\
\text { patients }\end{array}$ & \\
\hline Anti- $\beta 2-G P 1$ antibodies & $\begin{array}{l}3 / 27 \text { examined } \\
\text { patients }\end{array}$ & \\
\hline$\downarrow \mathrm{CH} 50 / \downarrow \mathrm{C} 3$ & $17 / 17$ & $28.3 / 28.3$ \\
\hline Immune complexes & 14 & 23.3 \\
\hline Haemolytic anaemia & 11 & 18.3 \\
\hline $\begin{array}{l}\text { Changes in capillaroscopy, } \\
\text { other than megacapillaries }\end{array}$ & 40 & 66.6 \\
\hline Changes in ECG & 5 & 8.3 \\
\hline Uveitis & 3 & 5 \\
\hline
\end{tabular}

Muscle weakness concerned $40 \%$ of children and most often included shoulder and pelvic girdle, but muscular pains were generalized in character. In individual patients, foci of calcinosis were observed.

In $10 \%$ of patients acute and recurring pericarditis was diagnosed, which in $75 \%$ of cases was accompanied by exudative pleuritis and periodically generalized lymphadenopathy. Disturbances of conduction were observed in ECG examination in over $8 \%$ of children. In $20 \%$ of children, symptoms of dryness were observed in the form of xerostomia. In almost $30 \%$ of children hypocomplementaemia and presence of immune complexes were observed. In none of the children were symptoms of renal inflammation observed.

Table V. Final observations (57 patients aged 18 and younger)

\begin{tabular}{|lcc|}
\hline Final observations & $n$ & Percentage \\
\hline $\begin{array}{l}\text { Complete lack of symptoms of the } \\
\text { disease, without medications }\end{array}$ & 4 & 7 \\
\hline $\begin{array}{l}\text { Stable improvement, taking } \\
\text { medications }\end{array}$ & 40 & 70.2 \\
\hline Exacerbations & 11 & 19.3 \\
\hline Death & 2 & 3.5 \\
\hline
\end{tabular}


Lung function impairment was observed in $20 \%$ of the examined children, mainly in the form of restrictive ventilation disorders. High-resolution computed tomography examinations revealed pulmonary fibrosis in individual patients. In $20 \%$ of patients we observed the presence of anti-SSA antibodies, which are considered to be a potential risk factor for pulmonary fibrosis. In laboratory tests results, the main marker of the disease, namely anti-RNP antibodies, was present in the titer from $1: 320$ to $1 \geq 10000$, in most cases above $1: 1280$. In patients with remission, the titer of the antibodies was lower, but in none of the patients was disappearance of antibodies observed.

In almost $80 \%$ of children, IgM-rheumatoid factor was present, more often than in other inflammatory connective tissue diseases. It was not observed in patients with complete remission of the disease.

In nailfold capillaroscopy assessment lesions were observed in over $80 \%$ of cases. Apart from megacapillaries, branched vessels were observed most often.

When assessing general symptoms at the onset of the disease according to Kasukawa's criteria, the highest number, over $80 \%$ of children, demonstrated symptoms suggesting SLE, about 40\% suggesting DM and about $25 \%$ suggesting SSc. In the period of observation the number of children with clinical symptoms suggesting SSc increased, especially with the symptoms of sclerodactyly and restrictive lung lesions, and in capillaroscopy also the number of branched loops.

In $70 \%$ of the patients we observed stable improvement; however, we had to maintain treatment. Remission, assessed according to the Wallace criteria for JIA [18], extended by the lack of aggravation of symptoms from lungs, esophagus and muscles as well as leuco- and thrombocytopenia, concerned $7 \%$ of patients. Frequent exacerbations were found in almost $20 \%$ of patients. Two children (3.5\%) died - sepsis caused by Streptococcus viridians was the cause of death in one case, and heart failure with mitral valve insufficiency in the $7^{\text {th }}$ year of the disease was the cause of death in the other case. In the second child, the death was caused by acute cardiac dysrhythmia and secondary heart failure.

\section{Discussion}

Diagnosing MCTD in children, especially at an initial stage of the disease, is very difficult, as the disease is very rare and its clinical symptoms are varied and present in many other rheumatic diseases. We have compared our own observations with large studies on MCTD in developmental age. Swart and Wulffraat [6] report time necessary for diagnosis of 1.7 years, which is similar to our observations.
Some clinical symptoms and irregularities in laboratory test results differed among various researchers. The data in the textbook by Petty [4] present the following frequencies: fevers in $56 \%$ of children with MCTD, arthritis in $93 \%$ of children, presence of rheumatoid factor in $68 \%$, weakening of muscles in $61 \%$, sclerodactyly in 49\%, restrictive lung function impairment in 14\%, similar frequency of SLE- and DM-type erythema in $33 \%$.

Hetlevik et al. [19] reported presence of fever at the onset of the disease in $29 \%$ of children, arthritis in $94 \%$ of children, presence of rheumatoid factor in $64 \%$, edema in hands in $77 \%$, weakening of muscles in over $40 \%$, sclerodactyly in $10 \%$, lung function impairment in $58 \%$ of children. $15 \%$ of children had remission, active disease was diagnosed in $67 \%$. The mortality rate was $5.1 \%$. Tellier et al. [20] reported presence of fever in $42 \%$ of children, arthritis in $68 \%$ of children, presence of rheumatoid factor in $37 \%$, edema in hands in $68 \%$, weakening of muscles in almost $70 \%$, sclerodactyly in $42 \%$ and lung function impairment in $37 \%$ of children. Continuously active disease was observed in $62 \%$ of patients. Mier et al. [21] observed, similarly to the present observations, symptoms of SSc at a later stage of the disease. Remission was observed only in $3 \%$ of patients.

The studies of other researchers, but also our own research, revealed that high titers of U1RNP antibodies and presence of RF at the time of diagnosis were related to high activity of the disease and were predictors of chronic activity.

However, as seen in these comparisons, the results of observations were not always similar. In children at an early stage of the disease, under 10 years of age, we did not observe differences in the course and subsequent consequences. Also duration of the disease did not influence its clinical picture.

There is no established treatment regimen for MCTD. Medications are prescribed depending on the observed clinical problems. Most of the children react well to low doses of GCS and we used them in all our patients in the subsequent course of the disease, after controlling the symptoms of high activity of the disease. In most of the cases, at the onset of the disease, children required high doses of GCS. Moreover, we used methotrexate, azathioprine, hydroxychloroquine and, when symptoms from muscles dominated, immunoglobulin infusions. Most of the children, in treatment of Raynaud syndrome, required the use of calcium channel blockers.

The results of our long-term observations revealed that most of our patients lead a normal lifestyle, learn or work, but continuously or periodically take GCS. 


\section{Conclusions}

Mixed connective tissue disease is very rare in children, and therefore the present results and observations may be particularly interesting. The long-term observation of MCTD patients in developmental age is a strong point of this study. The majority of patients had domination of SLE symptoms, in second place was DM and in third place mainly a SSc picture was present. Although in $70 \%$ of cases stable improvement was achieved, only $7 \%$ of MCTD patients achieved remission, which indicates the difficulty in prognosis of the disease, optimal treatment and interference of environmental factors such as infections. Serious infections with septic state were the cause of death in this group of patients.

The authors declare no conflict of interest.

\section{References}

1. Sharp GC, Irvin WS, Tan EM, et al. Mixed connective tissue disease - an apparently distinct rheumatic disease syndrome associated with a specific antibody to an extractable nuclear antigen (ENA). Am J Med 1972; 52: 148-159.

2. Singsen BH, Bernstein BH, Kornreich HK, et al. Mixed connective tissue disease in childhood. A clinical and serologic survey. J Pediatr 1977; 90: 893-900.

3. Fraga A, Gudiño J, Ramos-Niembro F, et al. Mixed connective tissue disease in childhood. Relationship Sjogren's syndrome. Am J Dis Child 1978; 132: 263-265.

4. Petty R, Laxer R, Lindsey C, et al. Textbook of Pediatric Rheumatology. Elsevier, Philadelphia 2016.

5. Flam ST, Gunnarsson R, Garen T, et al. The HLA profiles of mixed connective tissue disease differ distinctly from the profiles of clinically related connective tissue diseases. Rheumatology (Oxford) 2015; 54: 528-535.

6. Swart JF, Wulffraat NM. Diagnostic workup for mixed connective tissue disease in childhood. Isr Med Assoc J 2008; 10: 650-652.

7. Berard RA, Laxer RM. Pediatric Mixed Connective Tissue Disease. Curr Rheumatol Rep 2016; 18: 28.

8. Rutkowska-Sak L. Mieszana choroba tkanki łącznej w wieku rozwojowym - obraz kliniczny, przebieg, rokowanie. Nowa Medycyna - Reumatologia 1998; 20: 20-23.
9. Kotaima L, Aotsuka S, Sumiya M, et al. Clinical features of patients with juvenile onset mixed connective tissue disease: analysis of data collected in a nationwide collaborative study in Japan. J Rheumatol 1996; 23: 1088-1094.

10. Michels $\mathrm{H}$. Course of mixed connective tissue disease in children. Ann Med 1997; 29: 359-364.

11. Sharp GC. Diagnostic criteria for classification of MCTD. In: Kasukawa R, Sharp GC (eds.), Mixed connective tissue diseases and anti-nuclear antibodies. Elsvier Science Publishers B.V. (Biomedical Division), Amsterdam 1987: 23-32.

12. Alarcón-Segovia D, Villareal M. Classification and diagnostic criteria for mixed connective tissue disease. In: Kasukawa R, Sharp GC (eds.), Mixed connective tissue diseases and antinuclear antibodies. Elsvier Science Publishers B.V. (Biomedical Division), Amsterdam 1987: 33-40.

13. Kasukawa R, Tojo T, Miyawaki S. Preliminary diagnostic criteria for classification of mixed connective tissue disease. In: Kasukawa R, Sharp GC (eds.), Mixed connective tissue diseases and anti-nuclear antibodies. Elsvier Science Publishers B.V. (Biomedical Division), Amsterdam 1987: 41-47.

14. Kahn MF, Appelboom T. Syndrome de Sharp. In: Kahn MF, Peltier AP, Meyer O (eds.), Les Maladies Systemiques. Flammarion, Paris 1991: 545-546

15. Lage LV, Caleiro MT, Carvalho JF. Proposed disease activity criteria for mixed connective tissue disease. Lupus 2010; 19: 223-224.

16. Smolen JS, Steiner G. Mixed connective tissue disease: to be or not to be? Arthritis Rheum 1998; 41: 768-777.

17. Aringer M, Steiner G, Smolen JS. Does mibed connective tissue disease exist? Yes. Rheum Dis Clin North Am 2005; 31: 411420.

18. Wallace CA, Ruperto N, Giannini E. Preliminary criteria for clinical remission for select categories of juvenile idiopathic arthritis. J Rheumatol 2004; 31: 2290-2294.

19. Hetlevik SO, Flato B, Rygg M, et al. Long-term outcome in juvenile-onset mixed connective tissue disease: a nationwide Norwegian study. Ann Rheum Dis 2017; 76: 159-165.

20. Tellier S, Bader-Meunier B, Quartier P, et al. Initial presentation and outcome of pediatric-onset mixed connective tissue disease: a French multicenter retrospective study. Joint Bone Spine 2016; 83: 369-371.

21. Mier RJ, Shishov M, Higgins GC, et al. Pediatric-onset mixed connective tissue disease. Rheum Dis Clin North Am 2005; 31 : 483-496. 